\title{
ELECTROANALYSIS OF IBUPROFEN ON CONDUCTING POLYANILINE NANOFIBER COATED GLASSY CARBON SURFACE
}

\author{
E. SURESH'1, K. SUNDARAM1, B. KAVITHA ${ }^{* 2}$, N. SENTHIL KUMAR ${ }^{* 3}$
}

${ }^{1}$ Department of Chemistry, Karpagam University, Karpagam Academy of Higher Education, Coimbatore 641021, Tamil Nadu, India, ${ }^{2}$ Department of Chemistry, Sri Ranganathar Institute of Engineering and Technology, Coimbatore 641110, Tamil Nadu, India, ${ }^{3}$ Department of Chemistry, Arignar Anna Government Arts College, Cheyyar 604407, Tiruvannamalai (Dt.), Tamil Nadu, India Email: ootykavi@gmail.com

Received: 18 Jul 2016, Revised and Accepted: 20 Aug 2016

\begin{abstract}
Objective: Voltammetric procedure for analysis of pharmaceutical formulation of ibuprofen on conducting polyaniline nanofiber modified glassy carbon electrode was explored.

Methods: The effect of pH was studied at different medium such as acidic, neutral and basic. The cyclic voltammetric behavior of ibuprofen was studied between $-0.5 \mathrm{~V}$ and $1.8 \mathrm{~V}$ versus $\mathrm{Ag} / \mathrm{AgCl}$ at modified glassy carbon surface.

Results: The electroanalytical parameters of the detection are highly dependent on their configuration and dimensions of the electrode. The scan rate and concentration effect of ibuprofen were studied. The best limit of detection was $100 \mathrm{ppb}$ and the linear range from 200 to $400 \mathrm{ppb}$ on the modified electrode surface. The determination was successfully applied for the detection of drugs in several pharmaceutical drug formulations. The Atomic force microscopic (AFM) image shows the surface morphologies of polymer modified surface; compound adsorbed surface, particle distribution graphs and surface roughness values, which are in good agreement.
\end{abstract}

Conclusion: The anodic peak was observed at $1.63 \mathrm{~V}$, assigned for the oxidation of ibuprofen, which is not accompanied by corresponding cathodic reduction. This behavior suggested that the irreversibility of the electrode process.

Keywords: Ibuprofen, Voltammetry, Nanostructure, Nanofiber, Polyaniline, Differential Pulse Voltammetry, AFM

(C) 2016 The Authors. Published by Innovare Academic Sciences Pvt Ltd. This is an open access article under the CC BY license (http://creativecommons.org/licenses/by/4.0/) DOI: http://dx.doi.org/10.22159/ijcpr.2016v8i4.15276

\section{INTRODUCTION}

Electrode surface modification is a field of paramount importance in the modern electrochemistry, especially due to the various application possibilities of modified electrodes. In recent years, chemically modified glassy carbon electrodes have received increasing attention due to their potential applications in various analyses and also due to its relative ease of electrode preparation and regeneration [1]. Electrode surfaces coated with electropolymerized conducting polymer films have been paid great attention in the past, due to their unique physical and chemical properties and some possible applications in electrocatalysis, organic batteries, and microelectronic devices. Studies have indicated that surface coated polymer films exhibit enhanced analytical response for the quantification of various biological and clinical analytes. The thickness, permeation and charge transport characteristics of the polymeric films can be controlled by the potential and current applied [2-15]. Research on surface modified electrode has involved studies of the electrochemistry of the attached molecules, the catalysis and inhibition of various electrochemical processes and specific applications to such widely varying areas as photoelectrodes and analytical determinations $[16,17]$.

In recent years, modification of electrode surfaces has been an important research area in electrochemistry. Compared with other electrode concepts in electrochemistry, the distinguishing feature of a chemically modified electrode is that generally a thin film of a selected chemical is bonded or coated onto the electrode surface to endow the electrode with the chemical, electrochemical, optical, electrical, transport, and other desirable properties of the film in a rational, chemically designed manner $[18,19]$. One of the methods used for the modification of electrode surfaces is electropolymerization. Electropolymerization can accelerate transmission of electrons onto the surface of the electrode; it has high selectivity and sensitivity due to the film homogeneity in electrochemical deposition, and it has strong adherence to the electron surface and large surface area [20, 21]. Researchers have employed polymeric film modified electrodes to detect organic and inorganic molecules in recent years. Electrochemical methods, such as differential pulse polarography (DPP), stripping voltammetry (SV), differential pulse voltammetry (DPV) and square-wave voltammetry (SWV) have been widely applied for the determination of pharmaceuticals [22-38]. In the present investigation, a simple, effective and sensitive electrochemical method for the determination of ibuprofen on polyaniline nanofiber modified electrodes is explored.

\section{Experimental}

\section{Chemicals and apparatus}

All reagents were of AR grade purchased commercially. Solutions were prepared using deionized double distilled water. Stock standard solution of ibuprofen was prepared in $50 \%$ ethanol. A standard stock solution of ibuprofen $(1000 \mathrm{ppm})$ was prepared. The voltammetric studies were carried out in exploratory and determination mode on a software connected $\mathrm{CH}$ Instruments Electrochemical Workstation (model $\mathrm{CH}$ 650C). The voltammetric cell consisted of a three electrode assembly with polymer modified glassy carbon electrode as a working electrode, a platinum wire as an auxiliary electrode and $\mathrm{Ag} / \mathrm{AgCl}$ electrode as a reference electrode. Nitrogen gas was purged through the solution for $5 \mathrm{~min}$. A Hanna instrument $\mathrm{pH} / \mathrm{ORP}$ meter was used for $\mathrm{pH}$ measurements.

\section{Modification of the electrodes}

A GCE (3-mm diameter) was polished using 1.0 and $0.05 \mathrm{~mm}$ alumina slurry and rinsed thoroughly with Milli-Q water. Ultrasonic agitation for $30 \mathrm{~min}$ of $2.0 \mathrm{mg}$ of chemically prepared nanostructured polyaniline in $2 \mathrm{ml}$ of water gave a homogeneous green solution. $20 \mu \mathrm{L}$ of this solution was placed on the GCE surface. The electrode was then dried at room temperature to obtain a polymer modified GCE. 


\section{Pharmaceutical sample preparation}

One tablet of containing ibuprofen were weighed, powdered and then placed into a $250 \mathrm{ml}$ of the conical flask; warm water was added into the flask. The sample was swirled to dissolve for $30 \mathrm{~min}$ in sonicator and left cool. The sample solution was filtered through a filter paper (Whatman No.42) into $100 \mathrm{ml}$ volumetric flask. An aliquot of the solution was then analyzed according to the proposed voltammetric procedure.

\section{AFM topographic analysis}

The structural characterization of polyaniline nanofiber modified GCE and the modified surface adsorbed with ibuprofen was performed by atomic force microscopy (AFM). Nano Surf Easyscan 2AFM microscope operated in tapping mode under ambient conditions was employed. TopAl208 probes with a spring constant of $20-80 \mathrm{~N} / \mathrm{m}$ were used.

\section{RESULTS AND DISCUSSION}

\section{Characterization of electrode surfaces}

The electrode surfaces were characterized by AFM. AFM studies were conducted to give insight into the surface topography of the polymer surface and compound adsorption on the modified electrode surface. Fig. 1 shows the AFM image of polyaniline nanofiber and ibuprofen adsorbed on polyaniline nanofiber GCE. The polymer film is uniformly coated on the electrode surface and forms a nanofibrous morphology. The compound adsorbed surface exhibits similar morphological characteristics. This surface morphology accounts for the finding the active surface area of the composite electrode which is 7 times greater than the geometric area. The fig. shows the surface morphologies of polymer modified electrode, compound adsorbed surface, particle distribution graphs, and surface roughness values.

\section{Electrochemical behavior of ibuprofen}

The cyclic voltammogram of $200 \mathrm{ppm}$ ibuprofen in $\mathrm{pH} 1.0$ on polymer film modified electrode exhibits a single well defined anodic peak in the potential range- 0.5 to $1.8 \mathrm{~V}$. This anodic peak is assigned to the oxidation of ibuprofen at $1.63 \mathrm{~V}$ which is not accompanied by corresponding cathodic reduction. This behavior suggested that the irreversibility of the electrode process. Fig. 2 exhibits the cyclic voltammogram of polymer modified electrode (curve a), 200 ppm ibuprofen on polymer film modified (curve b) in pH 1.0. The polymer film modified surface shows a well defined and a sharp anodic peak is obtained

The peak current values were plotted against the scan rate in fig. 3 . Peak current values increased non-linearly with an increase in scan rate. Logarithmic values of peak currents were correlated well with the logarithmic values of scan rate, and it resulted in a linear line. These facts reveal that the voltammetric oxidation of ibuprofen is irreversible and controlled by a diffusion process.

\section{Differential pulse voltammetry (DPV)}

DPV is one of the most useful and convenient methods for sample identification. By employing this technique parts per billion (ppb), the range of a compound can be determined. The voltammetric behavior of drug allowed employing stripping analysis using polyaniline nanofiber modified GC electrode.

Cyclic voltammetric results revealed the diffusion-controlled of the substrate on polyaniline nanofiber modified GCE at aqueous ethanol medium $\mathrm{pH}$ 1.0. It was expected that ibuprofen would be adsorbed on the electrode during the accumulation step and stripped off easily in the stripping step. Thus the stripping voltammetric studies of ibuprofen were done at polyaniline nanofiber modified GCE in medium ethanol pH 1.0 using differential pulse stripping voltammetric method. The drug exhibits a very good stripping signal. A systematic study of various instrumental parameters that affect the stripping response has been carried out with $250 \mathrm{ppb}$ concentration of drug to establish the optimum conditions.

Effect of accumulation potential $\left(E_{\text {acc }}\right)$ and effect of accumulation time $\left(\mathrm{T}_{\text {acc }}\right)$

Hence optimization of the accumulation potential was done as the first part for this study. This potential was varied from- 0.5 to $1.8 \mathrm{~V}$ at an accumulation time of 15s. Maximum Peak current was observed at $1.4 \mathrm{~V}$ and it was fixed as the optimum accumulation potential.

By varying the deposition time from 15 to $75 \mathrm{~s}$, the effect of deposition time was studied after fixing the deposition potential at $1.4 \mathrm{~V}$. This table reveals highest current is observed at $15 \mathrm{~s}$ deposition time. Hence this is taken for the further consideration.

\section{Effect of initial potential $\left(E_{\text {in }}\right)$}

The initial scanning potential is another important parameter as it confirms the non-faradaic nature of the pre-concentration step. If also controls both the peak potential and peak current in the stripping voltammogram. The influence of the initial potential on the peak current was studied by varying the initial scan potential from0.8 to $1.5 \mathrm{~V}$. The peak current is affected by this initial potential in a different way. Better response ie, high peak current with the better resolution was observed at- $0.5 \mathrm{~V}$. Hence- $0.5 \mathrm{~V}$ was fixed as initial scanning potential and the reproducibility of the method was determined by making successive measurements.

\section{Effect of pulse height (PH) and effect of pulse width (PW)}

Effect of pulse height was studied by varying from 25 to $150 \mathrm{mV}$. The sharp peak current was observed at the pulse height of $100 \mathrm{mV}$. Similar to pulse height, pulse width also studied by varying from 25 to $150 \mathrm{~ms}$. The sharp peak nature with higher current was observed at a pulse width of $100 \mathrm{~ms}$. Hence the pulse width of $100 \mathrm{~ms}$ was chosen as an optimum value.

\section{Effect of scan increment (SI) and effect of pulse period (PP)}

The scan increment was varied between 4 to $16 \mathrm{mV}$ and maximum peak current response was obtained at $8 \mathrm{mV}$ scan increment. A study on the effect of pulse period in the range between 2 and $10 \mathrm{~s}$ was carried out. The stripping voltammetric signal showed the maximum peak current at $6 \mathrm{~s}$. The optimum conditions that resulted in good peak response were used to study the effect of analyte concentration. The range of study and the optimum values arrive at table 1.

\section{Analytical characteristic}

Under optimum experimental conditions, the influence of concentration on the stripping signal was studied. The experimental results showed that the peak current increased with the increase in the concentration of ibuprofen. A representative differential stripping voltammogram is given in fig. 4. A calibration was made, which indicated the linear dependence of peak current with concentration fig. 5. The range of determination was found in between $200 \mathrm{ppb}$ and $400 \mathrm{ppb}$. The lower limit of detection was 100 $\mathrm{ppb}$. The reproducibility of the stripping signal was understood from relative standard deviation $(2.1 \%)$ calculated for 7 identical measurements at a concentration level of $250 \mathrm{ppb}$.

The pharmaceutical samples were collected from medical shops and determined through DPV under optimum experimental conditions. Various tablets having ibuprofen were analysis to detection of the content of drug. Stripping voltammograms of the drugs at $\mathrm{pH} 1.0$ were recorded under optimized conditions. The concentration of the drug in commercial formulations determined by the proposed method was in good agreement with the reported value of the company (table 2).

Table 1: Optimum experimental conditions in DPSV

\begin{tabular}{lll}
\hline Parameters & Range studied & Optimum value \\
\hline pH & $1-13$ & 1.0 \\
Accumulation potential (V) & -0.8 to 1.8 & 1.4 \\
Accumulation time (Sec) & $10-60$ & 15 \\
Initial scan potential (V) & -0.5 to 1.5 & -0.5 \\
Pulse Height (PH) (mV) & 25 to 150 & 100 \\
Pulse width (PW) mSec & 25 to 150 & 100 \\
Scan Increment (SI) mV & 2 to 20 & 8 \\
Scan rate (SR) mV/sec & 10 to 100 & 50 \\
Stirring rate (rpm) & 50 to 250 & 250 \\
Rest period (Sec) & 2 to 10 & 5 \\
\hline
\end{tabular}


Table 2: Amount of IBP presented in tablets determined by DPSV

\begin{tabular}{llll}
\hline Brand name & Company name & Tablets (mg) & Experimental value (mg) \\
\hline Ibuorifen 400 & Modern laboratories & 400 & 391 \\
Brufen & Abbott India Ltd & 200 & 197 \\
Ibuorifen 200 & 200Modern laboratories & 200 & 1.7 \\
Ibuorifen & Synmedic laboratories & 200 & 196 \\
Ibugesic & Cipla & 200 & 195 \\
\hline
\end{tabular}
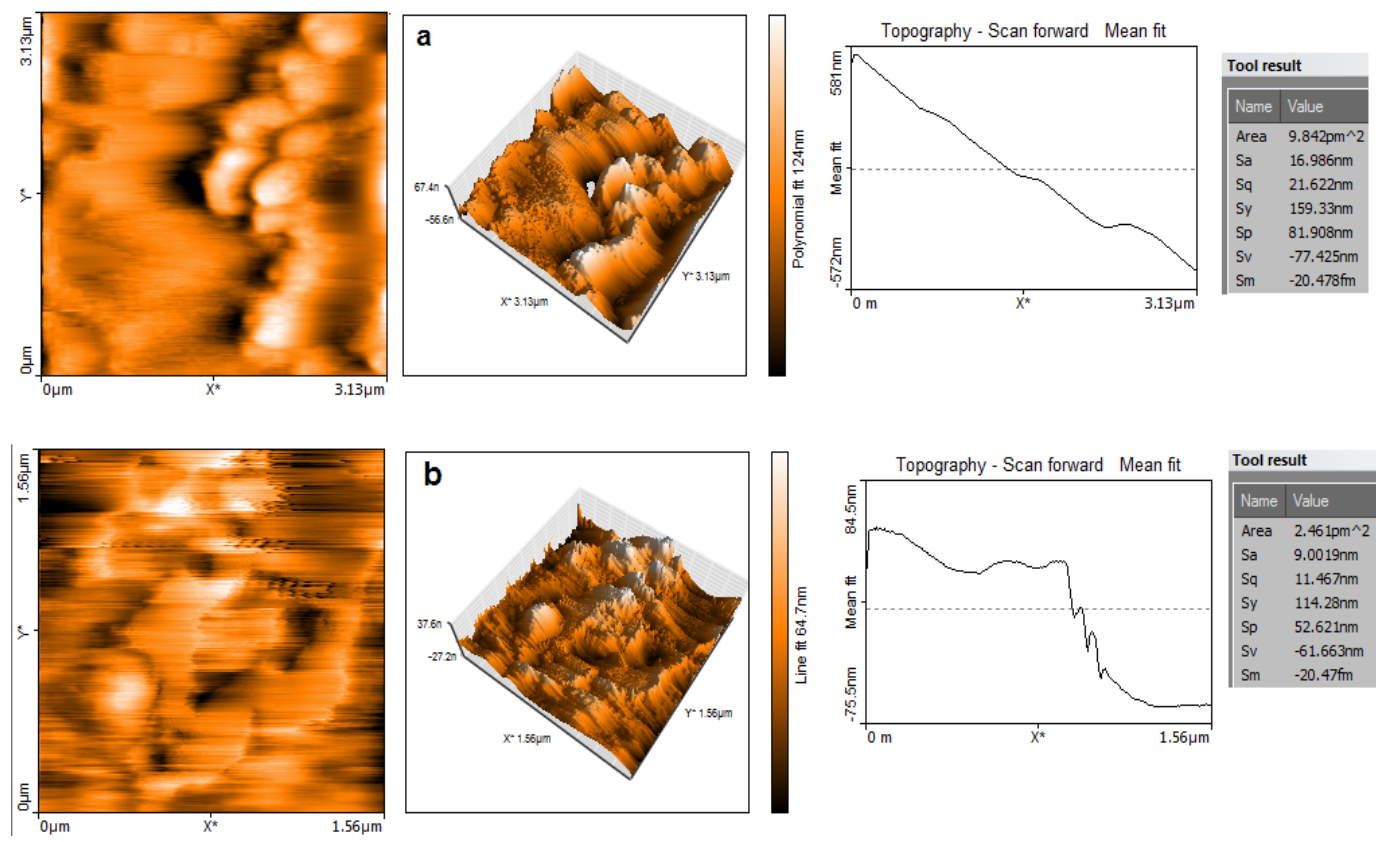

Fig. 1: AFM photographs of (a) polyaniline nanofiber modified GCE (b) Ibuprofen accumulated on electrode surface 2D, 3D, size distribution graph and surface roughness data

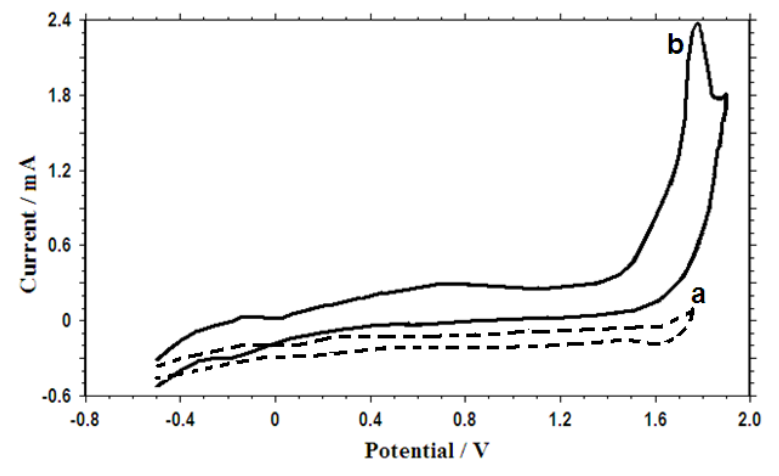

Fig. 2: Cyclic voltammetric behavior of (a) modified Glassy carbon electrode and (b) $200 \mathrm{ppm}$ of ibuprofen on polymer modified glassy carbon electrode in aqueous alcoholic pH 1.0 at $100 \mathrm{mV} / \mathrm{s}$

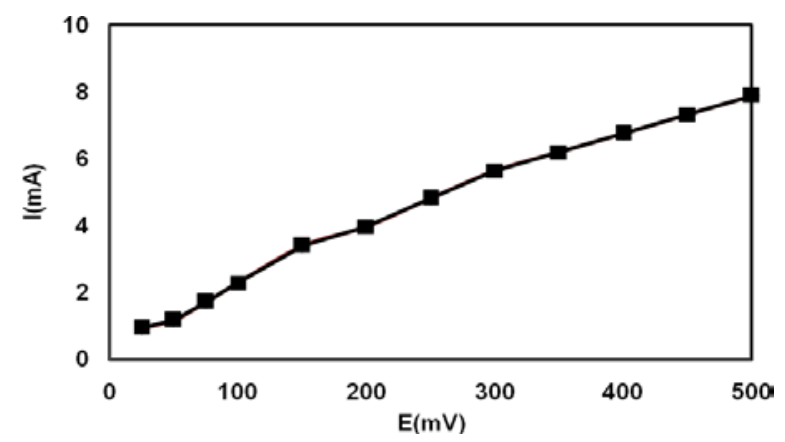

Fig. 3: Plot of peak current vs scan rate

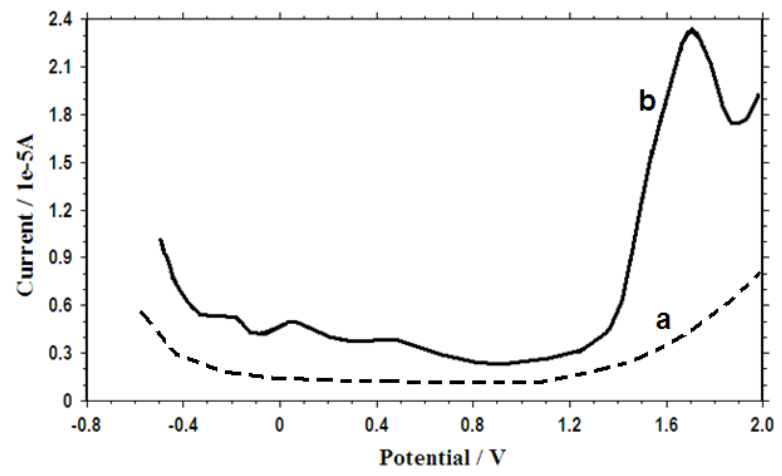

Fig. 4: Differential pulse stripping voltammetric behavior of (a) polymer coated surface (b) $250 \mathrm{ppb}$ ibuprofen on modified GCE under optimum condition

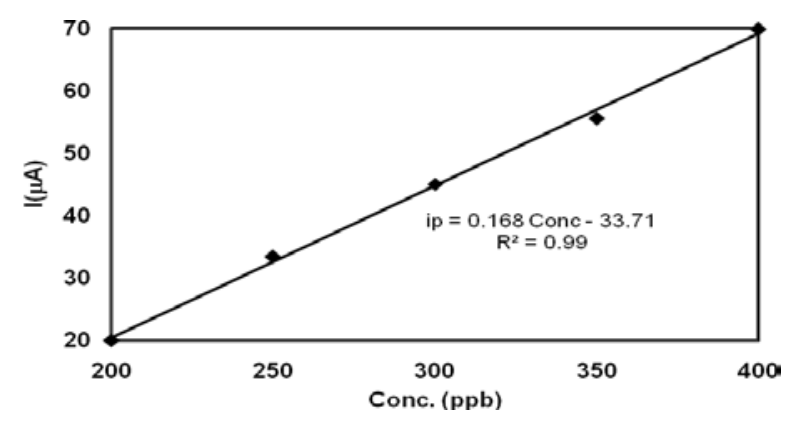

Fig. 5: Calibration plot of peak current vs conc 


\section{CONCLUSION}

The AFM topography shows the polymer film is uniformly coated on the electrode surface and forms a nanofibrous morphology. The compound adsorbed surface exhibits similar structural topography. The anodic peak was observed at $1.63 \mathrm{~V}$, assigned for the oxidation of ibuprofen, which is not accompanied by corresponding cathodic reduction. This behavior suggested that the irreversibility of the electrode process. The electrochemical response of ibuprofen at the modified surface reveals the irreversible and diffusion electrochemical process. The range of determination was found between $200 \mathrm{ppb}$, and $400 \mathrm{ppb}$, the lower limit of detection is 100 ppb through DPV.

\section{CONFLICT OF INTERESTS}

Declare none

\section{REFERENCES}

1. Jain R, Rather J. Voltammetric determination of antibacterial drug gemi-floxacin insolubilized systems at multi-walled carbon nanotubes modified glassy carbon electrode. Colloids Surf B 2011;83:340-6.

2. Manisankar P, Vedhi C, Selvanathan G, Gurumallesh Prabu H. Influence of surfactants on the electrochromic behavior of poly (3,4-ethylene dioxythiophene). J Appl Polym Sci 2007;104:3285-91.

3. Manisankar P, Vedhi C, Selvanathan G. Synthesis of a nanosize copolymer of 3,4-ethylenedioxythiophene with diclofenac and characterization. J Polym Sci Part A: Polym Chem 2007;45: 2787-96.

4. Manisankar P, Vedhi C, Selvanathan G, Gurumallesh Prabu H. Copolymerization of aniline and 4,4'-diamino diphenyl sulphone and characterization of formed nano size copolymer. Electrochim Acta 2006;52:831-8.

5. Manisankar P, Vedhi C, Selvanathan G, Gurumallesh Prabu H. Electrochemical synthesis and characterization of novel electrochromic poly (3, 4-ethylenedioxythiophene-co-Diclofenac) with surfactants. Electrochim Acta 2006;51:2964-70.

6. Manisankar P, Vedhi C, Selvanathan G, Somasundaram RM. The electrochemical and electrochromic behavior of novel poly (aniline-co-4,4'-diamino diphenyl Sulfone). Chem Mater 2005;17:1722-7.

7. Manisankar P, Vedhi C, Selvanathan G. Synthesis and characterization of novel nano size electroactive poly 4,4'diamino diphenyl sulphone. J Polym Sci Part A: Polym Chem 2005;43:1702-7.

8. Yu DB, Sun XQ, Zou JW, Wang ZR, Wang F, Tang K. Templatefree hydrothermal synthesis of octahedral $\mathrm{Fe}_{3} \mathrm{O}_{4}$ microcrystals and its magnetic property. J Phys Chem B 2006;110:21667-71.

9. Arruebo M, Gala'n M, Navascue's N, Tellez C, Marquina C, Ibarra MR, et al. Ordered mesoporous silica nanoparticles with and without embedded iron oxide nanoparticles: structure evolution during synthesis. J Chem Mater 2006;18:1911-9.

10. Vadivel M, Suresh Chandra Kumar M, Vedhi C, Selvam V, Dhaveethu Raja J. Development and corrosion performance of 3-aminopropyltriethoxysilane grafted gpoxidized ethylenepropylene-diene terpolymer rubber coatings. J Chem Pharm Sci 2015;7:200-2.

11. Dhaveethu Raja J, Senthilkumar GS, Vedhi C, Vadivel M. Synthesis, structural characterization, electrochemical, biological, antioxidant and nuclease activities of 3morpholinopropyl amine mixed ligand complexes. J Chem Pharm Res 2015;7:1-14.

12. Jessica Fernando, Vedhi C. Synthesis, spectral and electrochemical characterization of adipic acid doped polyaniline. Int J Sci Technol 2015;3:166-73.

13. Reddy TM, Balaji K, Jayarama Reddy SR. Differential pulse adsorptive stripping voltammetric determination of benzocaine and butacaine with nafion modified glassy carbon electrode. Croat Chem Acta 2006;79:253-9.

14. Tiwari DC, Jain R, Tiwari G. Electrochemical behavior of famotidine in the pharmaceutical formulation at composite polymer membrane electrode. Indian J Chem Technol 2008;5:472-5.
15. Huang $\mathrm{K}, \mathrm{Xu} \mathrm{C}$, Xie W, Wang W. Electrochemical behavior and voltammetric determination of tryptophan based on 4aminobenzoic acid polymer film modified glassy carbon electrode. Colloids Surf B 2009;74:167-71.

16. Esra Rukiye Apaydın, Gulsen Saglikoglu, Selehattin Yilmaz, Mustafa Yildiz. Sensitive electrochemical determination of oxcarbazepine using polymer film modified glassy carbon electrode. Int J Electrochem Sci 2015;10:1904-15.

17. Cigdem Demirtas, Selehattin Yilmaz, Gulsen Saglikoglu, Murat Sadikoglu. Electrochemical determination of phenazopyridine hydrochloride using poly(p-aminobenzene Sulfonic Acid) film modified glassy carbon electrode. Int J Electrochem Sci 2015; 10:1883-92.

18. Durst RA, Baumner AJ, Murray RW, Buck RP, Andrıeux CP. Chemically modified electrodes: recommended terminology and definitions. Pure Appl Chem 1997;69:1317-23.

19. Hou S, Zheng N, Feng H, Li X, Yuan Z. Determination of dopamine in the presence of ascorbic acid using poly(3,5dihydroxy benzoic acid) film modified electrode. Anal Biochem 2008;381:179-84.

20. Tetsuhiko Kobayashi, Hiroshi Yoneyama, Hideo Tamura. Polyaniline film-coated electrodes as electrochromic display devices. J Electroanal Chem 1980;115:279.

21. Lakshmi A, Gopu G, Thanikaikarasan S, Mahalingam T, Peggy Alvarez, Sebastian PJ, et al. Electroanalysis of diazepam on nanosize conducting poly (3-methylthiophene) modified glassy carbon electrode. J New Mater Electrochem Syst 2014;17:185-90.

22. Lakshmi A, Vedhi C. Synthesis and characterization of poly (3hexylthiophene) and used as modified electrode for determination of antidepressants in pharmaceutical formulations and urine samples. J Electrochem Soc 2013;160:H1-H6.

23. Lakshmi A, Anandha Raj J, Gopu G, Arumugam P, Vedhi C. Electrochemical, electrochromic behavior and effects of supporting electrolyte on nano-thin film of poly $(3,4-$ ethylenedioxy thiophene). Electrochim Acta 2013;92:452-9.

24. Mohamed Sikkander A, Vedhi C, Manisankar P. Cyclic voltammetric determination of 1, 4-Dihydro pyridine drugs using MWCNTs modified glassy carbon electrode. Chem Sin 2012;3:413-20.

25. Mohamed Sikkander A, Vedhi C, Manisankar P. Electrochemical stripping studies of amlodipine using mwcnt modified glassy carbon electrode. J Chem Mater Res 2011;1:1-7.

26. Mohamed Sikkander A, Vedhi C, Manisankar P. Utilization of sodium montmorillonite clay for enhanced electrochemical sensing of amlodipine. Indian J Chem 2016;55A:571-5.

27. Gopu G, Muralidharan B, Vedhi C, Manisankar P. Determination of three analgesics in pharmaceutical and urine sample on nano poly (3, 4-ethylenedioxythiophene) modified electrode. Ionics 2012;18:231-9.

28. Gopu G, Manisankar P, Muralidharan B, Vedhi C. Stripping voltammetric determination of analgesics in their pharmaceuticals using nano-riboflavin-modified glassy carbon electrode. Int J Electrochem 2011:1-11. http:// dx.doi.org/10.4061/2011/269452

29. Vedhi C, Anandha Raj J, Gopal N, Somasudaram RM, Manisankar P. Synthesis of potential capacitive poly 4, 4'-diaminodiphenyl sulphone-metal nanocomposites and their characterizations. Synth Met 2010;160:1307-12.

30. Anandh Raj J, Mathiyarau J, Vedhi C, Manisankar P. Electrochemical synthesis of nanosize polyaniline from aqueous surfactant solutions. Mater Lett 2010;64:895-7.

31. Muralidharan B, Gopu G, Vedhi C, Manisankar P. Determination of analgesics in pharmaceutical formulations and urine samples using nano polypyrrole modified glassy carbon electrode. J Appl Electrochem 2010;39:1117-84.

32. Muralidharan B, Gopu G, Vedhi C, Manisankar P. Voltammetric determination of analgesics and urine using a montmorillonite modified electrode. Appl Clay Sci 2008;42:206-13.

33. Ramadan AA, Mandil H. Determination of gatifloxacin in pure form and pharmaceutical formulations by differential pulse polarographic analysis. Anal Biochem 2010;404:1-7.

34. Liu X. A novel sensor based on the electropolymerization poly(safranine) film electrode for voltammetric determination of 4-nitrophenol. Bull Korean Chem Soc 2010;31:5. 
35. Pérez-Ortiz M, Munoz C, Zapata-Urzúa C, Álvarez-Lueje A. Electrochemical behavior of atomoxetine and its voltammetric determination in capsules. Talanta 2010;82:398-403.

36. Arvand M, Vaziri M, Vejdani M. Electrochemical study of atenolol at a carbon paste electrode modified with mordenite type zeolite. Mater Sci Eng C 2010;30:709-14.

37. Wen X, Fei J, Chen X, Yi L, Ge F, Huang M. Electrochemical analysis of trifluralin using a nanostructuring electrode with multi-walled carbon nanotubes. Environ Pollut 2008; $156: 1015-20$
38. Pradeep Kumar Brahman, Riyaz Ahmad Dar, Sweety Tiwari, Krishna Sadashiv Pitre. Voltammetric determination of anticancer drug flutamide in surfactant media at polymer film modified carbon paste electrode. Colloids Surf A 2012;396:8-15.

\section{How to cite this article}

- E Suresh, K Sundaram, B Kavitha, N Senthil Kumar Electroanalysis of ibuprofen on conducting polyaniline nanofiber coated glassy carbon surface. Int J Curr Pharm Res 2016;8(4):44-48. 